\title{
INDUCED DEFENSES IN HERBIVORES AND PLANTS DIFFERENTIALLY MODULATE A TROPHIC CASCADE
}

\author{
Irene van der Stap, ${ }^{1,3}$ Matthijs Vos, ${ }^{2,4}$ Antonie M. Verschoor, ${ }^{1}$ Nico R. Helmsing, ${ }^{1}$ and Wolf M. Mooij ${ }^{1}$ \\ ${ }^{1}$ Netherlands Institute of Ecology (NIOO-KNAW), Centre for Limnology, Department of Food Web Studies, Rijksstraatweg 6, \\ 3631 AC Nieuwersluis, The Netherlands \\ ${ }^{2}$ Department of Biology, University of Victoria, P.O. Box 3020, Victoria, British Columbia V8W3N5 Canada
}

\begin{abstract}
Inducible defenses are dynamic traits that modulate the strength of both plantherbivore and herbivore-carnivore interactions. Surprisingly few studies have considered the relative contributions of induced plant and herbivore defenses to the overall balance of bottom-up and top-down control. Here we compare trophic cascade strengths using replicated two-level and three-level plankton communities in which we systematically varied the presence or absence of induced defenses at the plant and/or herbivore levels. Our results show that a trophic cascade, i.e., significantly higher plant biomass in three-level than in two-level food chains, occurred whenever herbivores were undefended against carnivores. Trophic cascades did not occur when herbivores exhibited an induced defense. This pattern was obtained irrespective of the presence or absence of induced defenses at the plant level. We thus found that herbivore defenses, not plant defenses, had an overriding effect on cascade strength. We discuss these results in relation to variation in cascade strengths in natural communities.
\end{abstract}

Key words: bottom-up control; inducible defenses; interaction strength; phenotypic plasticity; predatorprey interactions; top-down control; trait-mediated interactions.

\section{INTRODUCTION}

Debates on trophic cascades have moved from the original question of whether communities are "green" because of complete top-down control (Hairston et al. 1960, Oksanen and Oksanen 2000) to investigations of the balance between bottom-up and top-down control across a variety of ecosystems (Brett and Goldman 1996, Schmitz et al. 2000, Halaj and Wise 2002, Shurin et al. 2002, 2006). Ecologists have also strongly focused on the biotic and abiotic factors that explain variation in cascade strengths within certain types of ecosystems (Power et al. 1992, Polis and Strong 1996, Chase 2003). Potential explanations for variation in the strength of community-wide trophic cascades include predator species diversity (Finke and Denno 2004, Bruno and O'Connor 2005, Byrnes et al. 2006, Snyder et al. 2006), herbivore species diversity (Schmitz et al. 2000), intraguild predation (McCann et al. 1998, Hart 2002), refuges against intraguild predation (Finke and Denno 2002, 2006), and heterogeneity in edibility within trophic levels (Leibold 1989, Power et al. 1992, Bell 2002, Vos et al. 2004b).

Manuscript received 13 October 2006; revised 25 May 2007; accepted 29 May 2007. Corresponding Editor (ad hoc): E. L. Preisser.

${ }^{3}$ Present address: Department of Biology, University of Miami, P.O. Box 249118, Coral Gables, Florida 33124 USA. E-mail: i.vanderstap@nioo.knaw.nl

${ }^{4}$ Present address: Netherlands Institute of Ecology (NIOO-KNAW), Centre for Estuarine and Marine Ecology, Korringaweg 7, 4401 NT Yerseke, The Netherlands.
The importance of variation in (induced) defenses and thus edibility as modulators of top-down control has been recognized for a long time (Murdoch 1966, Power et al. 1992, Strong 1992, Polis and Strong 1996, Bell 2002, Vos et al. 2002, 2004b, Schmitz et al. 2004). Under a regime of increasing predation, species that differ in their defense levels may change in relative abundance (Abrams and Vos 2003), or species turnover may change community composition altogether (Leibold et al. 1997, Chase et al. 2000). Through these community processes, plant and herbivore levels as a whole may change in terms of their edibility, even when defense levels of each of the comprising species are fixed.

Traits of individuals are rarely entirely fixed in nature. Phenotypic plasticity is in fact ubiquitous (Tollrian and Harvell 1999, Peacor and Werner 2000, Agrawal 2001), and defensive responses in both plants and herbivores often seem tuned to consumer density and thus predation risk (Schmitz et al. 2004, Vos et al. $2004 a, b)$. Consumers often seem to balance foraging activity and food intake against predation risk (e.g., Anholt et al. 2000). Carnivore-mediated reduction in herbivore feeding has two effects that differentially affect cascade strength. It may decrease carnivory, but it also decreases the consumption of plant biomass by "inactive" herbivores (Abrams 1984). In principle, this allows carnivores to have weak or strong, positive or negative effects on plant biomass, depending on the involved trade-offs (Schmitz et al. 2004). Nonetheless, whenever herbivores substantially reduce their feeding activity in the presence of carnivores, this may result in reduced plant damage levels, and even in increased plant 
growth or biomass. This would entail a behaviorally mediated trophic cascade (Schmitz et al. 2004).

Not all defenses, however, involve a reduced resource intake rate. Reduced feeding activity is a typical predetection or predator avoidance defense of otherwise vulnerable species. Species may also combine several defenses that interfere with different parts of the predation cycle, or may entirely rely on defenses that prevent ingestion (the final stage of the predation cycle). Such defenses should have qualitatively different effects on trophic cascades. For many plant and herbivore species, avoiding encounters with, and detection by, consumers is not an option. This may be the case because of a sedentary or planktonic (drifting) life style or for a suite of other reasons that require a reliance on defenses that interfere with the final stages of the predation cycle. Such defenses may include defensive colony formation in algae and the formation of defensive spines in zooplankton that hinder or prevent their ingestion by herbivores and gape-limited carnivores, respectively. Many defenses, including other changes in morphology, honest signals of strength, toxicity, or noxiousness, as well as flight or autotomy and other evasion tactics following encounters with predators are part of this defense category. None of these are likely to involve substantial costs in terms of reduced resource intake. Defenses in this category are not restricted to any particular ecosystem. They affect predation in freshwater, marine, and terrestrial food webs.

Terrestrial plants may also show indirect defenses, as many of these attract the parasitoids and carnivores of their insect herbivores through the emission of volatiles, after herbivore damage has started to occur (Vet and Dicke 1992, Dicke and Vet 1999, Vos et al. 2001, 2006). In the case of terrestrial plants, we can generally state that their defenses are unlikely to involve reduced nutrient uptake as a trade-off.

Post-encounter defenses may occur in plants or herbivores, or in both of these, in any particular food chain within a wider community. These defenses have important implications for the strength of trophic cascades and could entirely block the transmission of carnivore effects to the plant level. For example, when such defenses are strong in herbivores, this would make them independent of the top-down effects of secondary carnivores, whose role has been considered of major importance in differentiating pelagic communities from terrestrial ones (Hairston and Hairston 1997).

Here we evaluate the effects of induced defenses that act during the later stages of the predation cycle, i.e., defenses other than those that reduce activity levels. We focus on the effects of these defenses on the strength of trophic cascades using replicated two- and three-level planktonic food chains. We employ simple communities in order to disentangle the relative contributions of induced defenses in plants and herbivores, not because we think that real communities are simple (see Discussion). At the plant level, we use green algae from the

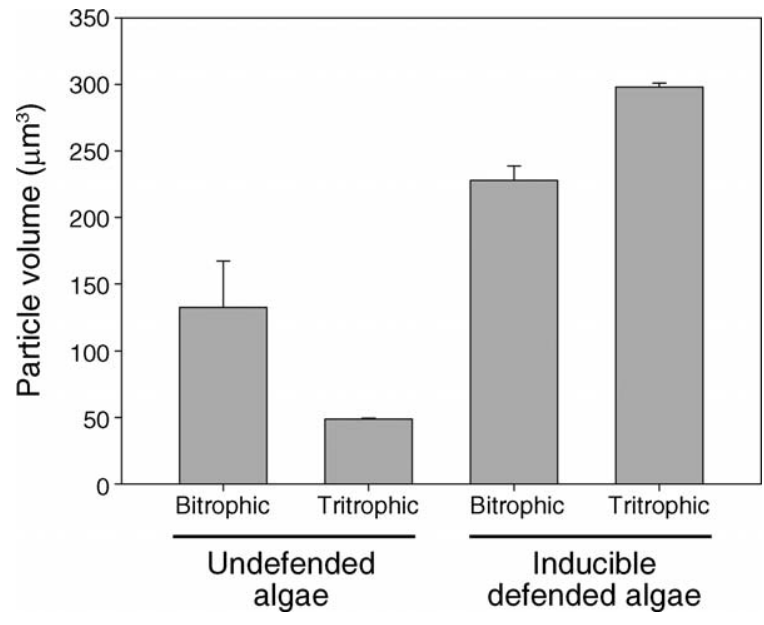

Fig. 1. A measure for plant defense: particle volumes of undefended algae (Desmodesmus) and of algae with inducible defenses (Scenedesmus) in two- and three-level food chains (bi- and tritrophic) with undefended herbivores (Brachionus rubens). Shown are means $(+\mathrm{SE})$ of three replicates, with each of these means being the particle volume averaged over the total duration of the experiment. Particle volumes differed significantly between algal strains (Mann-Whitney $U$ test, $P<0.01$ ).

Scenedesmaceae family, with Desmodesmus bicellularis being undefended while Scenedesmus obliquus forms defensive colonies in the presence of herbivorous zooplankton (Fig. 1; Verschoor et al. 2004a; see also Verschoor et al. 2004b: Fig. 2). At the herbivore level we use Brachionus rotifers, with $B$. rubens being undefended while B. calyciflorus forms defensive spines in the presence of carnivorous Asplanchna rotifers (Fig. 2; Gilbert 1966). At the carnivore level we use the gelatinous rotifer A. brightwellii. A previous experiment using a subset of these species led to the observation that induced defenses in algae had a major effect in terms of damping population fluctuations in food chains (Verschoor et al. 2004b). Nonetheless, algal defenses seemed to have little effect in terms of affecting algal biomass. This in turn led to our hypothesis that herbivore defenses in this data set had relatively strong effects and thus obscured the effect of plant defenses. We therefore performed a new experiment with a herbivorous rotifer without inducible defenses (B. rubens) in the same experimental set-up to investigate how the presence or absence of induced defenses in herbivores and plants affects the strength of trophic cascades.

\section{Methods}

Food chains in the present experiment were composed of the following organisms: (1) algae (often referred to as plants) comprising the undefended species Desmodesmus bicellularis Hegewald (Chlorococcales, Chlorophyta) strain UTEX LB1359, or inducible defended Scenedesmus obliquus (Turpin) Kützing (Chlorococcales, Chlorophyta) strain UTEX 2630; (2) undefended herbivorous zooplankton Brachionus rubens Ehrenberg (Rotifera); 


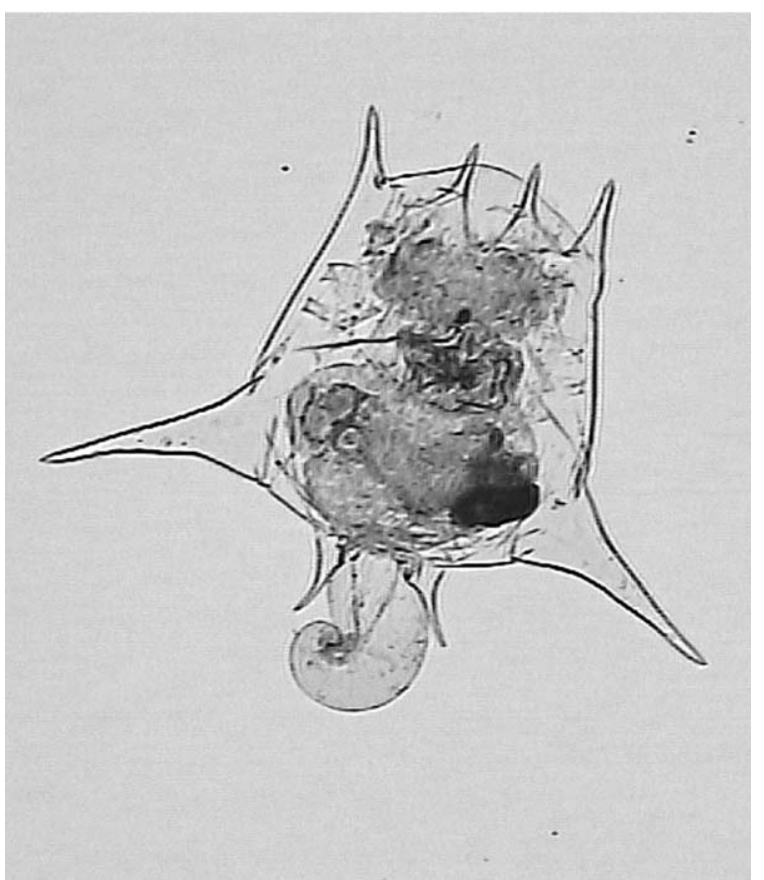

FIG. 2. Photograph of the herbivore Brachionus calyciflorus with induced postero-lateral spines that protect the rotifer from ingestion by the carnivorous rotifer Asplanchna. The presence of Asplanchna caused the percentage of defended B. calyciflorus herbivores to rapidly increase to more than $90 \%$ in the first three days. This high defense level was maintained during the entire experiment. Photo credit: N. R. Helmsing.

and (3) carnivorous zooplankton Asplanchna brightwellii Gosse (Rotifera). COMBO medium (Kilham et al. 1998) was used in all cultures and experiments. This system mimics the one studied by Verschoor et al. (2004b), but with the important difference that the herbivore in our study is undefended, whereas Verschoor et al. (2004b) used an inducible defended herbivore (B. calyciflorus). The rotifer $B$. rubens contains less carbon per individual than B. calyciflorus (Rothhaupt 1993), so we adjusted the initial densities of $B$. rubens in order to have initial carbon concentrations as in the experiment of Verschoor et al. (2004b).

The experiment was set up using a factorial design consisting of two algal defense strategies $\times$ two food chain lengths (two- and three-level) making four treatments. Algae were centrifuged for $10 \mathrm{~min}$ at 2500 $\mathrm{rpm}$ and resuspended twice in full medium containing 50 $\mu$ mol P/L. Zooplankton was added one day after algal inoculation. Inoculum densities were $0.5 \mathrm{mg} \mathrm{C} / \mathrm{L}$ for Scenedesmus and Desmodesmus, 2200 individuals/L (0.121 $\mathrm{mg} \mathrm{C} / \mathrm{L})$ for Brachionus and 10 individuals/L (0.0039 mg C/L) for Asplanchna. Three replicates of all treatments ran simultaneously in $1-\mathrm{L}$ microcosms for 14 days. Plankton was incubated at $21^{\circ} \mathrm{C}$ (minimum $20.5^{\circ} \mathrm{C}$, maximum $\left.21.5^{\circ} \mathrm{C}\right)$ in continuous light $(120 \mu \mathrm{mol}$ photons $[\mathrm{PAR}] \cdot \mathrm{m}^{-2} \cdot \mathrm{s}^{-1}$ [minimum 110 , maximum 130 $\mu \mathrm{mol}$ photons $\left.\cdot \mathrm{m}^{-2} \cdot \mathrm{s}^{-1}\right]$ ) and kept in suspension by gentle shaking (90 rpm [minimum $85 \mathrm{rpm}$, maximum $95 \mathrm{rpm}$ ). Every 24 hours, $100 \mathrm{~mL}(10 \%)$ of the plankton suspension was sampled and replaced by fresh medium. Phytoplankton and zooplankton samples were separated by a $30-\mu \mathrm{m}$ filter and fixed in $1 \%$ of Lugol's iodine solution. Algal subsamples were measured on a particle counter for the number of particles (unicells or colonies) and particle volume (CASY 1, Schärfe System Gmbh, Reutlingen, Germany). Particle volumes within each replicate were averaged over time and differed significantly between algal strains (Fig. 1; Mann-Whitney $U$ test, $P<0.01)$. Zooplankton samples were counted under a dissecting microscope.

The effect sizes of predator manipulations were measured as (1) the log of the ratio of average plant densities in the presence and absence of carnivores and (2) the log of the ratio of average herbivore densities in the presence and absence of carnivores. These measures are also referred to as cascade strength. Biomass levels of algae and herbivorous rotifers were determined by taking the average biomass over time for each replicate. The effects of algal strain (defenses present or absent) and number of trophic levels on biomass were analyzed using factorial ANOVA. Prior to analysis, data were tested for homogeneity of variances using Cochran's C test. Biomasses at each of the different trophic levels were analyzed using Tukey hsd post-hoc tests. Statistical analyses were performed using STATISTICA version 7.1 (StatSoft, Tulsa, Oklahoma, USA). We evaluated our results within this study in relation to those from a previous study, performed in exactly the same set-up and conditions, that used the inducible defended herbivore $B$. calyciflorus (population dynamics data published in Verschoor et al. 2004b; not previously analyzed for effects of defenses on trophic cascade strength). Within three days following inoculation with carnivorous Asplanchna, $90-100 \%$ of the B. calyciflorus population showed induced spines. Herbivore defense levels remained this high throughout the experiment. Undefended individuals had essentially no spines (lengths of $0-4$ $\mu \mathrm{m})$, whereas defended individuals had spines of 13-70 $\mu \mathrm{m}$, with a mean of about $35 \mu \mathrm{m}(n=240)$. Statistical comparisons were only made within each of the two data sets. For the analysis of the B. calyciflorus data set we again used cascade strength as defined above and average biomass levels over days 1 to 14 .

\section{Results}

\section{Presence or absence of a trophic cascade}

A strong trophic cascade was present when neither plants nor herbivores were defended, as indicated by the largest difference between plant biomass in absence and presence of carnivores, resulting in the highest positive log plant ratio value (Fig. 3a). Cascade strength decreased when plants had an induced defense, but only when herbivores were undefended (Fig. 3a). The trophic cascade disappeared altogether when herbivores had an 
induced defense, irrespective of whether plants were defended or not, as indicated by log plant ratio values close to zero (Fig. 3a). As expected, herbivore biomass was strongly negatively affected by carnivores when herbivores were undefended, and only weakly affected when herbivores had an induced defense (Fig. 3b).

These results are quantified using ANOVA (Table 1). When herbivores were undefended, food chain length significantly affected herbivore biomass (ANOVA, $P<$ 0.001 ) and plant biomass (ANOVA, $P<0.001$ ). In contrast, when herbivores had induced defenses, food chain length still affected herbivore biomass (ANOVA, $P<0.01$ ), but plant biomass was no longer affected (ANOVA, $P=0.60$ ).

The biomass of the different trophic levels is given in Fig. 4, left panels, showing a pattern of strong top-down control when herbivores were undefended. In this case we observed that the presence of carnivores decreased herbivore biomass (Tukey's hsd test, all $P$ values $\leq$ 0.001 ) and increased plant biomass, both when plants were undefended (Tukey's hsd test, $P<0.001$ ) and when they had an induced defense (Tukey's hsd test, $P<$ $0.01)$.

The alternative case, with induced defenses in herbivores, shows a pattern of weaker top-down effects that did not make it to cascade down to the plant level (Fig. 4, right panels). Here we observed that carnivores caused a marginally nonsignificant decrease in herbivore biomass when plants were undefended (Tukey's hsd test, $P=0.057)$ and a significant decrease in herbivore biomass when plants had an induced defense (Tukey's hsd test, $P=0.023)$. However, the addition of carnivores to a two-level food chain had no discernable effect on plant biomass, whether these plants were defended or not (ANOVA, $P=0.60$, Fig. 4f).

\section{Other biomass patterns}

We observed three striking patterns in biomass distribution apart from the absence or presence of a trophic cascade. First, carnivore biomass was significantly lower in a food chain based on algae with an induced defense than in a food chain based on undefended algae, but only when herbivores were undefended (ANOVA, $P<0.01$, Table 1, Fig. 4a), and not when herbivores were defended (ANOVA, $P=$ 0.65 , Table 1, Fig. 4b). Second, the undefended herbivore had a lower biomass in two-level food chains with inducible defended plants than in two-level food chains with undefended plants (Tukey's hsd test, $P<$ 0.001, Fig. 4c). This effect did not occur in the defended herbivore (Fig. 4d). Third, plant biomass was significantly lower in a food chain based on algae with an induced defense than in a food chain based on undefended algae, but only when herbivores had an induced defense (ANOVA, $P<0.001$, Table 1, Fig. 4f), and not when herbivores were undefended (ANOVA, $P$ $=0.64$, Table 1, Fig. 4e).
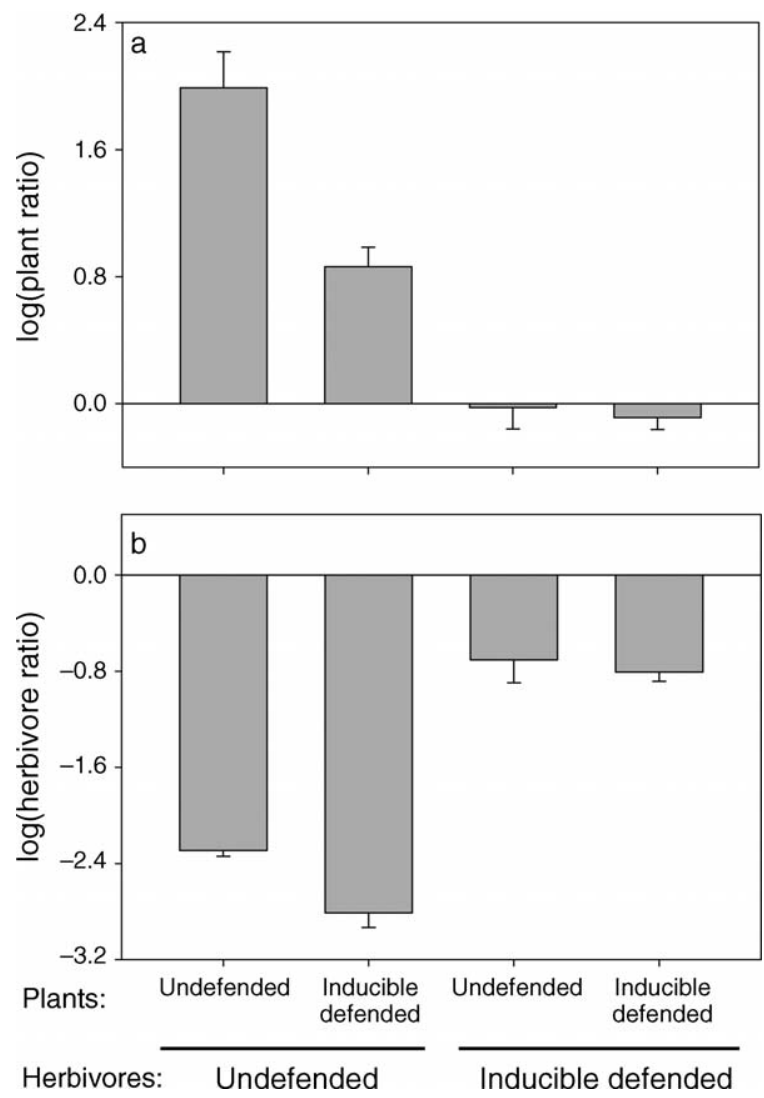

FIG. 3. Effect of inducible defenses on the strength of trophic cascades in food chains differing in the presence or absence of inducible defenses in (a) plants (algae) and (b) herbivores (zooplankton). Cascade strength was measured as (a) $\log$ (plant ratio), the mean plant biomass in the presence of carnivores divided by the mean plant biomass in the absence of carnivores, and (b) $\log$ (herbivore ratio), the mean herbivore biomass in the presence of carnivores divided by the mean herbivore biomass in the absence of carnivores. Shown are means (with SE) of three replicates.

\section{DisCUSSION}

\section{Trophic cascades}

Many biotic and abiotic factors cause cascade strengths to vary in nature. Top-down effects may come as trophic trickles or as strong trophic cascades and these top-down effects may be food chain specific or community wide. Nonetheless, in all of these cases we can ask how the traits of plants and herbivores within these communities contribute to overall effect sizes.

In the present study, we showed that herbivores with induced defenses caused a complete block of top-down carnivore effects on plants. In contrast, when herbivores were undefended this allowed a strong trophic cascade to exist. In this case the addition of a carnivore to a twolevel system resulted in herbivore suppression and increased plant biomass. The fundamental mechanism underlying the results of this study with defended herbivores is that herbivore defenses effectively prevent- 
TABLE 1. Summary of ANOVA testing the differences in biomass of all trophic levels (plants, herbivores, and carnivores) among plants (algal strains), food chain length (two- or three-level), and the interactions between algal strain and food chain length.

\begin{tabular}{|c|c|c|c|c|}
\hline Effects & $\mathrm{df}$ & MS & $F$ & $P$ \\
\hline \multicolumn{5}{|c|}{$\begin{array}{l}\text { Food chains with undefended herbivores } \\
\text { Plants (algae) }\end{array}$} \\
\hline $\begin{array}{l}\text { Algal strain } \\
\text { Food chain length } \\
\text { Strain } \times \text { food chain length } \\
\text { Error }\end{array}$ & $\begin{array}{l}1 \\
1 \\
1 \\
8\end{array}$ & $\begin{array}{c}0.759 \\
386.6 \\
29.34 \\
3.186\end{array}$ & $\begin{array}{c}0.2382 \\
121.4 \\
9.209\end{array}$ & $\begin{aligned} & 0.64 \\
< & 0.001 \\
< & 0.05\end{aligned}$ \\
\hline \multicolumn{5}{|l|}{ Herbivore (Brachionus rubens) } \\
\hline $\begin{array}{l}\text { Algal strain } \\
\text { Food chain length } \\
\text { Strain } \times \text { food chain length } \\
\text { Error }\end{array}$ & $\begin{array}{l}1 \\
1 \\
1 \\
8\end{array}$ & $\begin{array}{l}0.5375 \\
2.231 \\
0.3134 \\
0.0069\end{array}$ & $\begin{array}{c}77.67 \\
322.5 \\
45.29\end{array}$ & $\begin{array}{l}<0.001 \\
<0.001 \\
<0.001\end{array}$ \\
\hline \multicolumn{5}{|l|}{ Carnivore (Asplanchna) } \\
\hline $\begin{array}{l}\text { Algal strain } \\
\text { Error }\end{array}$ & $\begin{array}{l}1 \\
4\end{array}$ & $\begin{array}{l}0.0184 \\
0.0003\end{array}$ & 59.70 & $<0.01$ \\
\hline \multicolumn{5}{|c|}{$\begin{array}{l}\text { Food chains with inducible defended herbivores } \\
\text { Plants (algae) }\end{array}$} \\
\hline $\begin{array}{l}\text { Algal strain } \\
\text { Food chain length } \\
\text { Strain } \times \text { food chain length } \\
\text { Error }\end{array}$ & $\begin{array}{l}1 \\
1 \\
1 \\
8\end{array}$ & $\begin{array}{c}1414 \\
3.257 \\
0.006 \\
11.02\end{array}$ & $\begin{array}{r}128.3 \\
0.2954 \\
0.0006\end{array}$ & $\begin{array}{c}<0.001 \\
0.60 \\
0.98\end{array}$ \\
\hline \multicolumn{5}{|c|}{ Herbivore (Brachionus calyciflorus) } \\
\hline $\begin{array}{l}\text { Algal strain } \\
\text { Food chain length } \\
\text { Strain } \times \text { food chain length } \\
\text { Error }\end{array}$ & $\begin{array}{l}1 \\
1 \\
1 \\
8\end{array}$ & $\begin{array}{l}0.1861 \\
8.401 \\
0.0732 \\
0.3568\end{array}$ & $\begin{array}{c}0.5215 \\
23.54 \\
0.2050\end{array}$ & $\begin{array}{r}0.49 \\
<0.01 \\
0.66\end{array}$ \\
\hline \multicolumn{5}{|l|}{ Carnivore (Asplanchna) } \\
\hline $\begin{array}{l}\text { Algal strain } \\
\text { Error }\end{array}$ & $\begin{array}{l}1 \\
4\end{array}$ & $\begin{array}{l}0.0005 \\
0.0021\end{array}$ & 0.2427 & 0.65 \\
\hline
\end{tabular}

ed ingestion by carnivores while not limiting the herbivore's intake of algal food. If, in contrast, a carnivore-induced defense would reduce the herbivore's feeding rate on plants, this could allow plant biomass to increase. In the latter case, a behavioral-mediated trophic cascade would occur. We thus have the somewhat counterintuitive situation that herbivore defenses may either prevent or facilitate a trophic cascade, depending on whether there is a trade-off between the defense and the herbivore's food intake. Defenses that act early in the predation cycle usually involve such a trade-off, while many defenses that act later on in the predation cycle hardly affect resource intake rates. The system with Asplanchna as a carnivore and spined B. calyciflorus as a defended herbivore is an example of the latter situation.

In this model system, herbivore defenses were more efficient in preventing ingestion by carnivores than algal defenses were in preventing ingestion by herbivores. In principle, a highly efficient plant defense could similarly buffer top-down effects on its biomass by species higher up in the food web. Cascade strength is often observed to attenuate at the plant-herbivore interface, both in aquatic (Brett and Goldman 1996) and in terrestrial (Schmitz et al. 2000) communities. Our results show that induced herbivore defenses alone can cause such an attenuation of cascade strength at the herbivore- carnivore interface. We showed this in a simple model system using food chains that are otherwise highly comparable, e.g., with respect to their stoichiometry.

Natural communities are complex and diverse, and as our study shows, not all herbivore species are equally defended. However, effective induced defenses occurring in a variety of herbivore species within a community could substantially dampen top-down control. In the present study, we worked with a limited number of species, i.e., we analyzed data from a food chain with a single herbivore species that represented the undefended defense type and related these results to data from a food chain with a single defended herbivore species. The extent to which our results can be extended to community-wide trophic cascades depends on the ways in which dominant plant and herbivore species respond to multispecies complexes of their consumers. Many defenses, such as toxins and spines, are likely to be effective against a wide variety of consumer species. This is also the case for reduced activity defenses such as described by Abrams (1984) and Schmitz et al. (2004). Since reduced activity and defenses that act later on in the predation cycle can have opposite effects on cascade strength, the community-wide effects of herbivore defenses will depend on the relative abundance and importance of different herbivore species employing these different kinds of defenses. This implies that 

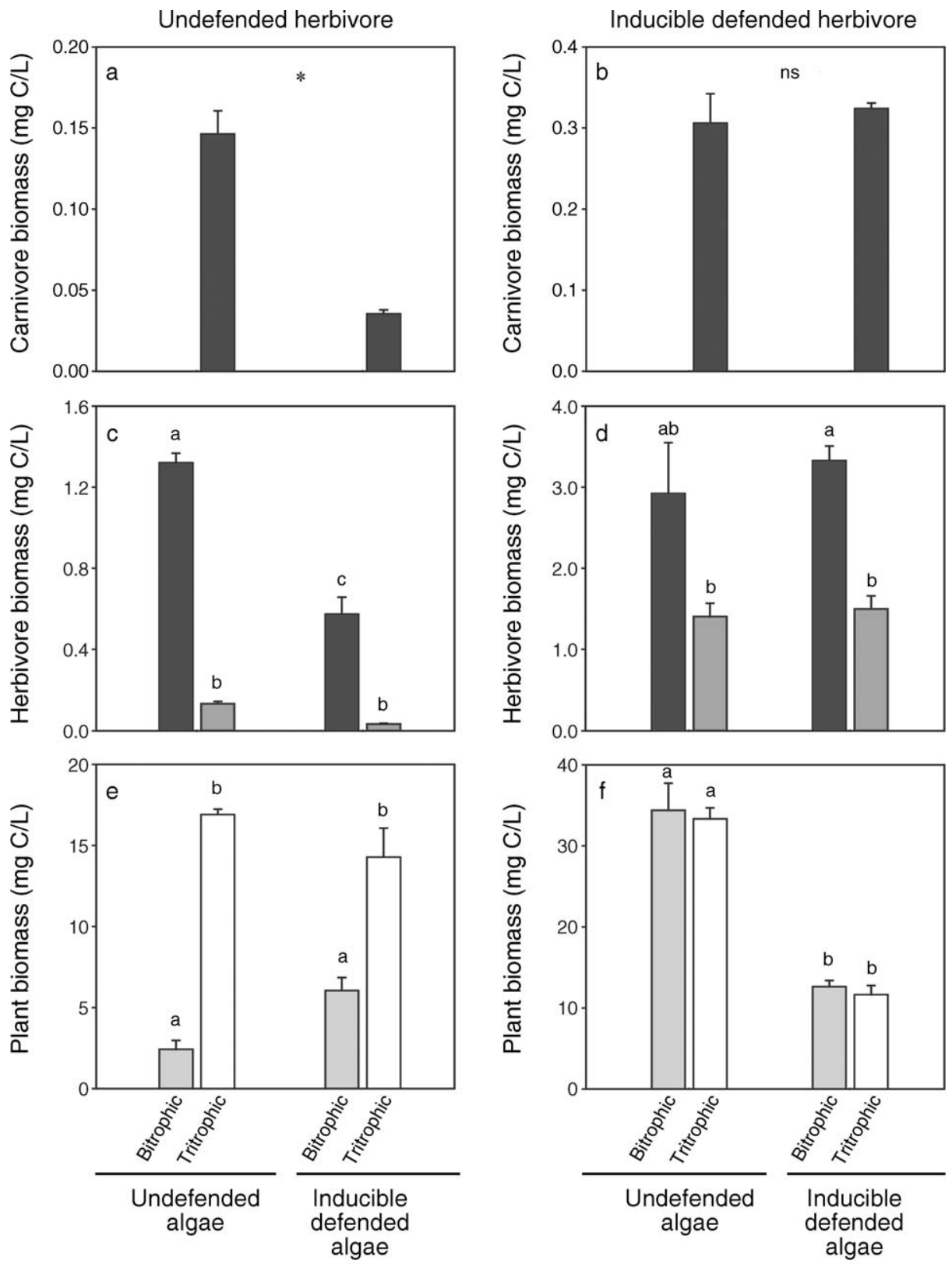

FIG. 4. Biomass of all trophic levels, with carnivores (top row), herbivores (middle row), and plants (bottom row). The left panels show two- and three-level food chains with either undefended or inducible defended plants and an undefended herbivore; the panels to the right show these food chains with the inducible defended herbivore (based on data from Verschoor et al. [2004] not previously analyzed for cascade strength). Shown are means (+SE) of three replicates. Different letters within panels indicate significant differences $(P<0.05)$ among treatments (Tukey's hsd test after ANOVA).

analyses of cascade strength need to take into account how herbivores defend themselves against their consumers. It similarly means that "herbivore diversity" cannot be a simple variable in analyses of top-down and bottom-up control.

\section{Other biomass patterns}

We found that both herbivore biomass in two-level food chains and carnivore biomass in three-level food chains were lower when these food chains were based on inducible defended algae (as compared to chains based on undefended algae, see Fig. 4a, c). This effect of plant defenses on the accumulation of biomass higher up in the food chain only occurred when herbivores were undefended. This effect can be understood from the fact that the undefended herbivore $B$. rubens is smaller than the defended herbivore B. calyciflorus and is thus more affected by defensive colony formation in algae. $B$. rubens has previously indeed been shown to have a lower 
ingestion rate than $B$. calyciflorus on large algae (Rothhaupt 1990).

In food chains with defended herbivores, plant biomass was significantly higher when these chains were based on undefended algae. This was the case in both two-level and three-level food chains (Fig. 4f). This biomass pattern can be understood from the underlying pattern in population dynamics. Both two-level and three-level food chains showed highly fluctuating population densities when these were based on undefended algae, while those based on inducible defended algae monotonically approached a stable equilibrium (Verschoor et al. 2004b). The high densities of undefended algae we observed are related to low herbivore densities that occurred during these population fluctuations. This makes clear that any analysis of trophic cascade strength has to take into account whether the underlying population dynamics are stable or cyclic, because "measured cascade strength" will be affected by the duration of the experimental period in systems that show cyclic dynamics in nature. Short-term experiments (relative to the organisms' life and population cycles) would be especially vulnerable to sampling either peaks or troughs of population cycles. However, we emphasize here that our main result in this paper, the presence or absence of a trophic cascade depending on the presence or absence of herbivore defenses, was independent of population stability: The effect of herbivore defenses on cascade strength occurred no matter whether the algal population was undefended or inducibly defended, and thus also irrespective of whether population fluctuations occurred or were absent.

\section{Conclusion}

We conclude that both the presence and the type of herbivore defenses can be important in determining the relative effects of bottom-up and top-down control, and thus the strength of trophic cascades. Herbivore defenses strongly inhibited top-down control by carnivores in our model system, thereby effectively preventing the trophic cascade that was strongly present when herbivore defenses were absent. Our results make clear how herbivore defenses that prevent ingestion by carnivores (with no trade-off in the herbivore's rate of plant consumption) will effectively attenuate trophic cascades at the herbivore-carnivore interface. This study indicates the importance of discriminating between herbivore defenses that act late in the predation cycle (e.g., by preventing ingestion through morphological changes) and those that act early on in the predation cycle (e.g., by preventing detection through reduced feeding activity), as these may have qualitatively different effects on cascade strengths in natural communities. The predation cycle is a fundamental aspect of feeding in any kind of food web, whether it is part of a freshwater, marine or terrestrial ecosystem. In all of these systems, herbivore defenses may counteract predation during early and/or later stages of this cycle, with or without trade-offs on herbivory rates. The differential effects of these different kinds of defenses should be of importance to any comparison of trophic cascade strengths within and between ecosystems in nature.

\section{ACKNOWLEDGMENTS}

We are grateful to Ralph Tollrian for kindly providing us with strains of $B$. rubens and A. brightwellii. We thank Daniel Gruner and an anonymous reviewer for their comments on the manuscript. M. Vos is grateful to Brad Anholt for many stimulating discussions, for changing our perspective on preencounter and post-encounter defenses, and for providing a great working environment at the University of Victoria. I. van der Stap was supported by Earth and Life Sciences grant 812.04.008 from the Netherlands Organisation for Scientific Research (NWO-ALW). This is publication no. 4073 of the Netherlands Institute of Ecology (NIOO-KNAW).

\section{Literature Cited}

Abrams, P. A. 1984. Foraging time optimization and interactions in food webs. American Naturalist 124:80-96.

Abrams, P. A., and M. Vos. 2003. Adaptation, density dependence and the responses of trophic level abundances to mortality. Evolutionary Ecology Research 5:1113-1132.

Agrawal, A. A. 2001. Ecology: phenotypic plasticity in the interactions and evolution of species. Science 294:321-326.

Anholt, B. R., E. Werner, and D. K. Skelly. 2000. Effect of food and predators on the activity of four larval ranid frogs. Ecology 81:3509-3521.

Bell, T. 2002. The ecological consequences of unpalatable prey: phytoplankton response to nutrient and predator additions. Oikos 99:59-68.

Brett, M. T., and C. R. Goldman. 1996. A meta-analysis of the freshwater trophic cascade. Proceedings of the National Academy of Sciences (USA) 93:7723-7726.

Bruno, J. F., and M. I. O'Connor. 2005. Cascading effects of predator diversity and omnivory in a marine food web. Ecology Letters 8:1048-1056.

Byrnes, J., J. J. Stachowicz, K. M. Hultgren, A. R. Hughes, S. V. Olyarnik, and C. S. Thornber. 2006. Predator diversity strengthens trophic cascades in kelp forests by modifying herbivore behaviour. Ecology Letters 9:61-71.

Chase, J. M. 2003. Strong and weak trophic cascades along a productivity gradient. Oikos 101:187-195.

Chase, J. M., M. A. Leibold, and E. Simms. 2000. Plant tolerance and resistance in food webs: community-level predictions and evolutionary implications. Evolutionary Ecology 14:289-314.

Dicke, M., and L. E. M. Vet. 1999. Plant-carnivore interactions: evolutionary and ecological consequences for plant, herbivore and carnivore. Pages 483-520 in H. Olff, V. K. Brown, and R. H. Drent, editors. Herbivores: between plants and predators. Blackwell Science, Malden, Massachusetts, USA.

Finke, D. L., and R. F. Denno. 2002. Intraguild predation diminished in complex-structured vegetation: implications for prey suppression. Ecology 83:643-652.

Finke, D. L., and R. F. Denno. 2004. Predator diversity dampens trophic cascades. Nature 429:407-410.

Finke, D. L., and R. F. Denno. 2006. Spatial refuge from intraguild predation: implications for prey suppression and trophic cascades. Oecologia 149:265-275.

Gilbert, J. J. 1966. Rotifer ecology and embryological induction. Science 151:1234-1237.

Hairston, N. G., Jr., and N. G. Hairston, Sr. 1997. Does food web complexity eliminate trophic-level dynamics? American Naturalist 149:1001-1007.

Hairston, N. G., F. E. Smith, and L. B. Slobodkin. 1960. Community structure, population control, and competition. American Naturalist 94:421-425. 
Halaj, J., and D. H. Wise. 2002. Impact of a detrital subsidy on trophic cascades in a terrestrial grazing food web. Ecology 83:3141-3151.

Hart, D. R. 2002. Intraguild predation, invertebrate predators, and trophic cascades in lake food webs. Journal of Theoretical Biology 218:111-128.

Kilham, S. S., D. A. Kreeger, S. G. Lynn, C. E. Goulden, and L. Herrera. 1998. COMBO: a defined freshwater culture medium for algae and zooplankton. Hydrobiologia 377:147159.

Leibold, M. A. 1989. Resource edibility and the effects of predators and productivity on the outcome of trophic interactions. American Naturalist 134:922-949.

Leibold, M. A., J. M. Chase, J. B. Shurin, and A. L. Downing. 1997. Species turnover and the regulation of trophic structure. Annual Review of Ecology and Systematics 28: 467-494.

McCann, K. S., A. Hastings, and D. R. Strong. 1998. Trophic cascades and trophic trickles in pelagic food webs. Proceedings of the Royal Society B 265:205-209.

Murdoch, W. W. 1966. Community structure population control and competition: a critique. American Naturalist 100:219-226.

Oksanen, L., and T. Oksanen. 2000. The logic and realism of the hypothesis of exploitation ecosystems. American Naturalist 155:703-723.

Peacor, S. D., and E. E. Werner. 2000. Predator effects on an assemblage of consumers through induced changes in consumer foraging behavior. Ecology 81:1998-2010.

Polis, G. A., and D. R. Strong. 1996. Food web complexity and community dynamics. American Naturalist 147:813-846.

Power, M. E., J. C. Marks, and M. S. Parker. 1992. Variation in the vulnerability of prey to different predators: communitylevel consequences. Ecology 73:2218-2223.

Rothhaupt, K. O. 1990. Changes of the functional responses of the rotifers Brachionus rubens and Brachionus calyciflorus with particle sizes. Limnology and Oceanography 35:24-32.

Rothhaupt, K. O. 1993. Steady-state growth and carbon metabolism of Brachionus rubens and B. calyciflorus. Pages 123-132 in N. Walz, editor. Plankton regulation dynamics: experiments and models in rotifer continuous cultures. Springer-Verlag, Berlin, Germany.

Schmitz, O. J., P. A. Hambäck, and A. P. Beckerman. 2000. Trophic cascades in terrestrial systems: a review of the effects of carnivore removals on plants. American Naturalist 155: $141-153$.
Schmitz, O. J., V. Krivan, and O. Ovadia. 2004. Trophic cascades: the primacy of trait-mediated indirect interactions. Ecology Letters 7:153-163.

Shurin, J. B., E. T. Borer, E. W. Seabloom, K. Anderson, C. A. Blanchette, B. Broitman, S. D. Cooper, and B. S. Halpern. 2002. A cross-ecosystem comparison of the strength of trophic cascades. Ecology Letters 5:785-791.

Shurin, J. B., D. S. Gruner, and H. Hillebrand. 2006. All wet or dried up? Real differences between aquatic and terrestrial food webs. Proceedings of the Royal Society B 273:1-9.

Snyder, W. E., G. B. Snyder, D. L. Finke, and C. S. Straub. 2006. Predator biodiversity strengthens herbivore suppression. Ecology Letters 9:789-796.

Strong, D. R. 1992. Are trophic cascades all wet? Differentiation and donor-control in speciose ecosystems. Ecology 73: $747-754$.

Tollrian, R., and C. D. Harvell. 1999. The ecology and evolution of inducible defenses. Princeton University Press, Princeton, New Jersey, USA.

Verschoor, A. M., I. Van der Stap, N. R. Helmsing, M. Lürling, and E. Van Donk. 2004a. Inducible colony formation within the Scenedesmaceae: adaptive responses to infochemicals from two different herbivore taxa. Journal of Phycology 40: 808-814.

Verschoor, A. M., M. Vos, and I. Van der Stap. $2004 b$. Inducible defences prevent strong population fluctuations in bi- and tritrophic food chains. Ecology Letters 7:1143-1148.

Vet, L. E. M., and M. Dicke. 1992. Ecology of infochemical use by natural enemies in a tritrophic context. Annual Review of Entomology 37:141-172.

Vos, M., B. J. G. Flik, J. Vijverberg, J. Ringelberg, and W. M. Mooij. 2002. From inducible defences to population dynamics: modelling refuge use and life history changes in Daphnia. Oikos 99:386-396.

Vos, M., B. W. Kooi, D. L. DeAngelis, and W. M. Mooij. 2004a. Inducible defences and the paradox of enrichment. Oikos 105:471-480.

Vos, M., S. Moreno Berrocal, F. Karamaouna, L. Hemerik, and L. E. M. Vet. 2001. Plant-mediated indirect effects and the persistence of parasitoid-herbivore communities. Ecology Letters 4:38-45.

Vos, M., A. M. Verschoor, B. W. Kooi, F. L. Wäckers, D. L. DeAngelis, and W. M. Mooij. 2004b. Inducible defenses and trophic structure. Ecology 85:2783-2794.

Vos, M., L. E. M. Vet, F. L. Wäckers, J. J. Middelburg, W. H. van der Putten, W. M. Mooij, C. H. R. Heip, and E. van Donk. 2006. Infochemicals structure marine, terrestrial and freshwater food webs. Ecological Informatics 1:23-32. 